\title{
Assessing the Relationship between Organizational Commitment, Stressors and Technological Stress In Organizations
}

\author{
Abadllahi Umar, ${ }^{1}$ Ibrahim Sale, ${ }^{2}$ Yakubu Yahaya ${ }^{3}$ \\ ${ }^{I}$ Department of Technology Management, Faculty of Technology Management and Business, University Tun \\ Hussein Onn Malaysia (UTHM) \\ ${ }^{2}$ Department of Business Administration and Management, School of Management Studies, Abubakar Tatari \\ Ali Polytechnic Bauchi, Bauchi State, Nigeria \\ ${ }^{3}$ Department of Business Administration and Management, School of Management Studies, Abubakar Tatari \\ Ali Polytechnic Bauchi, Bauchi State, Nigeria
}

\begin{abstract}
This study examines the relationship between organizational Commitment (OC), Stressors (ST) and Technological stress (TNS) in Nigerian organizations. The study is based on 50 samples drawn from Nigerian postgraduate students of University Tun Hussein Onn Malaysia (UTHM), who are on study leave. Quite surprisingly, however, one finds little empirical research with conceptual models of the relationships between OC, TS and TNS. This study is premised on Person - Environment fit model which either occurs between the values of a person, and the environmental resources available, or between the abilities of the person, and the demands placed by the environment. A model was proposed and two questions were asked and empirically answered. Q1: Does strong relationship exist between OC and TS in organizations. Q2: Does relationship exist between OC and TNS that affect adoption behavior in firms. SPSS software was employed for the analysis. Despite the varying views of the respondents on the influence of additional factors, it was generally demonstrated that relationships exist between OC, TS and TNS.
\end{abstract}

Keywords: Organizational Commitment, technology, Technostress, Stressors,

\section{Introduction}

Research in organizational commitment (OC) has consistently enjoyed attention of both scientists and practitioners more than ever before. According to [1], of all the branches of commitment, it is the OC that is currently enjoying widest popularity. This is justifiable considering the numerous studies that have examined the correlation between OC and a number of its antecedents and outcomes [2]. Perceiving OC as an attitude which can predict turnover better than other work attitudes, especially better than job satisfaction [3] has exponentially increased the quest to deepen findings that relates it with technological innovations. Moreover, it has been argued that organizations whose members have higher levels of commitment will show higher performance and productivity, and lower levels of absenteeism and lethargy [4,5] that could result in drastic reduction in technostress and associated resistance to any change, whatsoever. An organizational commitment is conceived as having the tendency to mold behavior considering the exchange of relationship between the employee and the organization. This depicts "an affective or emotional attachment to the organization such that the strongly committed individual identifies with, is involves in, and enjoys membership in the organization" [6]. Positive exchanges with organizations motivate employees through affective organizational commitment, in-role performance. It is likely; however, that this orientation will also enhance employees' morale to contribute to the organization [7] in a way that maximum attention is accorded to emerging technologies; hence, minimizing technology stress. To achieve the objectives of this research, this paper is divided into five sections; in addition to section one which introduced the research, it contains sections two, three, four and five that focus on relevant literature, research design, analysis and discussion and conclusion respectively.

Amidst the persistent technological changes evident in the proliferation of different technologies, Techno-stress among workers in organizations is becoming more alarming especially in organizations that fail to appreciate its implications. Extant literature has recognized a number of factors that either cause the inability of users to cope with the new technologies in a stress-free manner, or even truncates the successful adoption by end-users. According to [8], techno-stress has a dual manifestation: in the struggle to accept computer technology, and in the more specialized form of obsession with computer technology. This study focuses on the former, which relates to clinical symptoms of phobia exhibited by technology users as a new form of resistance [9] likely to occur when new technologies are being introduced. 


\subsection{Problem Statement}

Computer technology has become a rapidly changing and important field. The application of these technologies, which often renew themselves in both software and hardware, is a source of pressure for both individual workers and social settings [10]. Empirical evidences have shown that the pressure caused by intensive use of technology or the phobia and anxiety exhibited as new technologies are introduced, is a great source of concern to individuals, societies and business organizations. A lot of studies have been conducted using diverse approaches to mitigate the adverse effects of technological evolutions (technostress) to end users. Amazingly, researchers develop little interest in examining the correlation between this phenomenon and OC, albeit recognizing that the two may correlate as they are all behavior oriented concepts [11].

\section{Relevant Literature}

This study views organizational commitment as conceptualized by Mowday et al. [12] and [11]; they conceived it from two perspectives --- behavioral and attitudinal commitments. According to these researchers, behavioral commitment has to do with the processes by which employees become part of a specific organization by internalizing some appropriate behaviors, while attitudinal commitment on the other hand relates to the processes by which employees come to think about their relationships with their organization, and the extent to which their goals and values are consistent with those of the organization [11]. The other aspect of this study is stress-related. Psychological stress generally, has been defined according to [13], as the kind of relationship between individuals and their environment that is appraised by internal and external disequilibrium resulting from individuals' deficient resources, thereby endangering their well being. In the present technology age, technology-specific stress has reached an alarming stage that calls for solutions. This stress is either evident in the struggle to accept computer technology or in the over-fascination with computer technology. This study falls within the stream of studies that lay emphasis on technophobia, cyber-phobia, computer-phobia, computer anxiety, computer stress, negative computer attitudes, and computer aversion among others [4].

\subsection{Organizational Commitments In Innovative Organizations}

Innovative organizations here connote firms that use new technologies which attract people seeking for some thrilling places to learn rapidly and make a personal impact, while on the other hand risk the possibility of experiencing technostress, when equilibrium is distorted. Equilibrium is only possible where the nature of the psychological contract entered into by employees, e.g. the beliefs held by individuals about the terms and conditions of a reciprocal exchange relationship between them and their organization are categorically delineated and appreciated and fulfilled by all parties [14] .

Literature has it that transactional and relational contract are the basis for discussing OC in innovative firms with a view to relieving workers of technology associated stress. Transactional contracts in this context defines the short term arrangement with limited involvement, oriented towards economic and performance based considerations, while relational contracts entails agreements based on exchanges of both financial and socioemotional elements (affection, loyalty, support) that are sustained over a long period and have a wide range of mutual obligations and benefits that control and guide individuals in the work environment [15]. In other developments, some authors concluded that workers who exhibited higher commitment to their organizations were also found to have higher loyalty and lower work stress [16] and were disposed to accept organizational change [17].

Stress in whatever form is detrimental to employees' well being; and it influences their work efficiency and relationships with others [18]. The same conception was held by [19], in their view of stress as a mental and physical situation which influences an individual's health, work and quality of life. Relating the above understanding with technology related stress, [20] concisely define stress (technostress) as the direct or indirect negative effect of technology use on human behavior, thought, attitude and psychology. All these areas require managers' implacable commitment. This might prove more effective when the three-dimensional measurement of organizational commitment is used to mirror and enhance workers' commitment. [21] defined the three dimensions as:- (1)Affective commitment, e.g. "positive feelings of identification with, attachment to, and involvement in the work organization". (2) Continuance commitment, e.g. "the extent to which employees feel committed to their organizations by virtue of the costs that they feel are associated with leaving (investments or lack of attractive alternatives)". (3) Morale commitment, e.g. "the employees' feelings of obligation to remain in the organization". These eventually culminate into honored psychological contract that solidly determines employees' behaviors [22], improves satisfaction and reduces physical and psychological stress associated with use of technologies. This extrapolation could be consolidated by [23] and [24], in their report that, the higher levels of stress have been associated with lower organizational commitment. Inversely, higher OC could be associated with lower TNS. 


\subsection{Causes Of Technostress In SSEs}

Undoubtedly, many studies opine that technostress in some instances is associated with work environment which can only be addressed by the organization. [25] Suggested the rate of change of the technology, lack of standardization, lack of training individuals on the equipment, lack of reliability of the technology and increased workload placed on each individual as measures that measure stressors. In a separate study, [26] states that technostress is caused by technologically focused tasks such as planning meetings, business plans, and anxiety over work deadlines. Other stressors were identified by defining technostress as a condition whereby a person has to adapt to new technology especially when there is inadequacy of equipment, support, or the technology itself [27]. Further, research has also looked into the relationship between supervisor and supervised as a source of strain. Explicitly, authoritarian and autocratic leadership styles of supervision are deemed unhealthy to organizations and a very good source of strain [28].

Other researchers conceived TNS as employees' inability to cope with or be familiar with information and communication technologies (ICT), thereby complicating actual technology adoption [29;30]. In the same research, five stressors were outline -- 1. Techno-overload: A situation where ICT users are induced to work extensively. 2. Techno-invasion: A situation that undermines work life quality by mixing work-related and personal contexts. 3. Techno-complexity: A situation relating technology features and users' competence. 4 . Techno-insecurity: A situation where ICT users feel threatened job insecurity and fear of been substituted by better hands. 5. Techno-uncertainty: A situation where ICT users feel hesitant and disconcerted due to continuous changing and upgrading.

\subsection{Symptoms of Technostress in SSEs}

The sign and symptoms of technological stress cut across a wide range of physiological, psychological and behavioral issues that have been empirically identified as unhealthy human conditions. These issues are manifested in the form of physical and emotional exhaustion that involve a negative self concept and negative attitudes as well as loss of concern and feeling for others. Long-term stress may cause psychosomatic illness [31].

A lot of write-ups have been dedicated to finding out the manifestations of technological stress in workers. Extant study includes a high degree of factual thinking, poor access to feelings, an insistence on efficiency and speed, and a lack of empathy for other people. People with these are known as technocentered; their desire to triumph over the applications is more pronounced than the desire for human relationships and human pleasures [4]. Prior descriptive findings on technostress have been largely consistent in their resolve to prove that stressful impact can be felt at all levels of an organization, as Stress related health costs are increasing exponentially and productivity in stressed individuals diminish drastically $[32 ; 33]$

So, organizations have incentives to better understand symptoms at workplace both from workers well being and associated expenditures. A review of some findings revealed some dominant symptom as panic, anxiety, feeling of isolation/frustration, negative attitude towards computers, irritability, anger, exhaustion, increased errors, absenteeism, illness, low morale/confidence, depression, turnover intentions, bad attitude, lack of motivation, Work exhaustion $[34 ; 35 ; 36]$

\section{Research Design}

The aim of the present work is to develop a model that depicts relationship between organizational commitment and relevant technological stress. Emphasis is on explaining how OC influence technological stress and stressors by way of developing a model of causal relationship. Survey methodology that adopt crosssectional design was used to collect data from the representative sample at one point; as it is the most widely used methodology for stress studies [37]. Convenience sampling technique was employed to select Fifty (50) males and females postgraduate students of UTHM, who at one term or the other worked with innovative organization in Nigeria. Attempts have been made to achieve the research objectives using the existing literature and administration of questionnaires. The self- administered questionnaires were analyzed with SPSS statistical software.

\subsection{Model and Hypotheses Development}

Broadly speaking, this section unfolds the application of the concept of person- environment model and accompanying hypotheses. In essence, it is argued that there is 'equilibrium' between an individual and his work environment. Any imbalance in this equilibrium leads to strain [37;38]. In our context, we are focused on individual's interaction with technology in work settings. Therefore, if an individual faces imbalance in interaction with technology, he is exposed to technological stress (technostress). A model was proposed and hypotheses were developed for each relationship as depicted by the framework below. Regarding the research variables, however, scales exist for most of the constructs identified in the research model; so they are adapted 
based on the descriptive accounts of technostress from the existing literature of related concepts. The commitment related constructs were adapted from [39], while the stress related ones were adapted from [32].

\subsubsection{Proposed Model}

One of the objectives of this research as stated earlier is to propose a model that depicts the relationships between the constructs of the study. Below is the model:

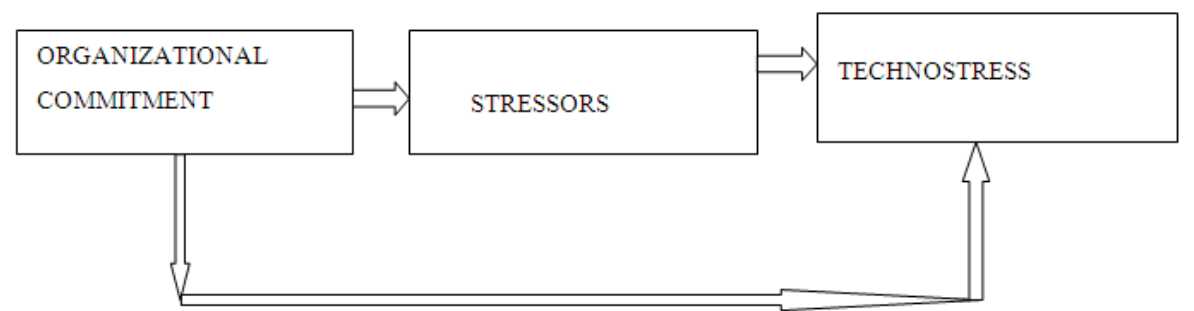

Figure 3.1: Proposed Commitment-Technostress Model

\subsubsection{Hypotheses}

To answer the research questions earlier formulated, four situations were hypothesized and empirically tested.

H1: There is negative relationship between Organizational Commitment and Work-overload that causes technological Stress

H2: Organizational Commitment is negatively correlates with Work-home conflict that result in technostress in SSEs.

H3: There is positive correlation between Organizational Commitment and Technical Support in SSEs.

H4: Inverse relationship exists between Organizational Commitment and Technological stress in Nigerian SSEs.

\section{Analysis And Discussion}

The purpose of this section is to present the questionnaire survey results and to analyze these using SPSS. Out of 65 survey questionnaires administered, 55 returned surveys have been received. However, after ruling out those with insufficient data, 50 valid questionnaires were identified, which reflected a usable response rate of $77 \%$. The first part of this section provides the test of the constructs validity so as to authenticate if the constructs have the required consistency to achieve the research objectives. The second part relates to the results of the questionnaire survey which depicts the Pearson correlations among the various constructs of the study. In the third part, our research hypotheses were tested against the obtained results to inform their acceptance or rejection. Finally, the section concluded by discussion of the links existing in the proposed model.

\section{1 constructs Consistency}

The Cronbach's alpha for each of the constructs are shown in Table 4.1. None of the constructs exhibited any serious problem, such as lack of sufficient validity. Even though there are two constructs that measured 0.578 and 0.587 , they are all within acceptable limits in social science research [40; 41].

Table 4.1 Cronbach's Alpha

\begin{tabular}{|l|l|l|}
\hline VARIABLE & CODE & $\begin{array}{l}\text { CRONBACH'S } \\
\text { ALPHA }\end{array}$ \\
\hline Organizational Commitment & COMMITM & 0.578 \\
\hline Technical Support & TECHSUP & 0.767 \\
\hline Work-home conflict & WHCON & 0.587 \\
\hline Work Overload & WORKL & 0.686 \\
\hline Stress Symptoms & SYMSTR & 0.867 \\
\hline
\end{tabular}

\subsection{Correlations between Constructs}

The relationship between organizational commitment (as measured by COMMTM), technical support (as measured by the TECHSUP), work-home conflict (as measured by WHCON), work overload (as measured by WORKL) and stress symptoms (as measured by SYMSTR) were investigated using partial correlation. Preliminary analyses were performed to ensure adherence to some basic assumptions. The results of the analyses revealed three categories of relationships. These categorizations were based on [42], who suggested the following guidelines: Small $r=0.10$ to 0.2 , Medium $r=0.30$ to 0.49 and Large $r=0.50$ to 1.0. 
Table 4.2 Correlations

\begin{tabular}{|c|c|c|c|c|c|c|}
\hline & & COMMITM & WORKL & WHCON & TECHSUP & SYMSTR \\
\hline \multirow{4}{*}{ COMMITM } & Pearson Correlation & 1 & & & & \\
\hline & Sig. (2-tailed) & & & & & \\
\hline & $\mathrm{N}$ & 50 & & & & \\
\hline & Pearson Correlation & -.100 & 1 & & & \\
\hline \multirow[t]{3}{*}{ WORKL } & Sig. (2-tailed) & .515 & & & & \\
\hline & $\mathrm{N}$ & 50 & 50 & & & \\
\hline & Pearson Correlation & .158 & $.517^{* *}$ & 1 & & \\
\hline \multirow[t]{3}{*}{ WHCON } & Sig. (2-tailed) & .274 & .000 & & & \\
\hline & $\mathrm{N}$ & 50 & 50 & 50 & & \\
\hline & Pearson Correlation & -.157 & $.331^{*}$ & .120 & 1 & \\
\hline \multirow[t]{3}{*}{ TECHSUP } & Sig. (2-tailed) & .278 & .019 & .407 & & \\
\hline & $\mathrm{N}$ & 50 & 50 & 50 & 50 & \\
\hline & Pearson Correlation & .023 & .010 & $.311^{*}$ & .265 & 1 \\
\hline \multirow[t]{2}{*}{ SYMSTR } & Sig. (2-tailed) & .874 & .943 & .028 & .063 & \\
\hline & $\mathrm{N}$ & 50 & 50 & 50 & 50 & 50 \\
\hline
\end{tabular}

It is very clear from table 5.2, that significance of the correlation is strongly influenced by the size of the sample. Normally in a small sample (e.g. $n=30$ ), moderate correlations that do not reach statistical significance at the traditional $\mathrm{p}<.05$ level is expected; while in large samples $(\mathrm{N}=100+)$, however, very small correlations (e.g. $\mathrm{r}=.2$ ) may reach sound statistical significance [43]. Bearing this in mind, this study suggests that a small negative correlation $(r=-0.100)$ exists between organizational commitment (COMMITM), as an independent variable and one of the constructs of stressors (WORKL), as a dependent variable. In general, Organizational commitment has shown weak correlations with all the other constructs of the study. For example, $\mathrm{r}=0.158$ with WHCON, $\mathrm{r}=0 .-157$ with TECHSUP and a neglegeable one, $\mathrm{r}=0.023$ with SYMSTR. The strongest correlation in this study is between WHCON and WORKL, showing $r=.517, \mathrm{~N}=50, \mathrm{p}<0.01$. This is followed by relationships between TECHSUP and WORKL, and between TECHSUP and WHCON, measuring $\mathrm{r}=.331, \mathrm{~N}=50, \mathrm{p}<0.05$ and $\mathrm{r}=.311, \mathrm{~N}=50, \mathrm{p}<0.05$ respectively.

\section{Discussion And Coclusion}

The basic purpose of this study was to examine the relationships between Organiztional Commitment (OC), Stressors (STR) and Technostress (TNS) in the Nigerian small scale enterprises (SSEs) . The first relationship found was aweak negative relationship (-0.10) between OC and WORKL ( a construct of STR), as was expected. Although the negative relationship recorded was small considering the Cohen's categorization (cohen, 1988); one simplistic explanation for this finding is that participants used in this study were graduate students that were on study leave only, hence, only small sample size was available to the researcher. This viewpoint is in tandem with the reason given by[43].

The second relationship in this study examined the direct-path relationship between OC and WHCON (second construct of STR). Although it was originally hypothesized that OC would negatively relate to WHCON, the actual relationship appeared to be possitive. Inspite of that, the correlation was so small (0.158) to make the hypothesis meaningless [44], as the explanation for this development could be attrbuted to the study sample size too.

To test the third hypothesis which states that, there will be statistically significant correlation between OC and TECHSUP (third construct of STR) given by SSEs, result in table 4.2 indicated that the the two constructs were inversely related to each other. A relationship of $r=-0.157$ was suggestive of the rejection of the third hypothesis made in this study. This result showed that the higher the organizational commitment, the lower the technical support given to the worker. Inspite of this mixed result, a good explanation to the situation was given by [45], in their goal setting theory book. The theory suggested that the more complex the task, the more committed workers become and by default, the less technical support is required to accomplish the task. Lastly, hypothesis four that hypothesized the existence of negetive correlation between OC and SYMSTR (symptoms of technostress) was authenticated otherwise. Our correlation table recorded a possitive relationship 
of $r=0.023$ instead of a negetive figure as hypothesized. The same explanation of in-significant correlation despite the change in the direction of the relationship is very intrumental here [44].

In conclution, it is imperative to mention here that organizations have wholeheartedly embraced technology in view of the significant influence it has on the processes and outcomes of organizational life. Nevertheless, technostress is important fallout of the inevitable use of technology in organizations that aspire to integrate in the global business circle. Attention is definitely needed to balance the two situations. This research represents an attempt to develop conceptual and empirical comprehensions of technostress and its outcomes across the Nigerian SSEs. In line with the obtained result, the questions raised in this study could be answered in the affirmative. We believe that the model and relationships developed in this paper can be used as bases for informed decisions that are well grounded on sound ideologies. Obviously, the relationships in this study appeared skewed in some cases; it could be blamed on small size of the sample used in the study. It is hoped that our attempt would tickle other researchers to undertake the same research using a reasonable sample size that could give a more superior result.

\section{References}

[1] A. Cohen, Antecedents of organizational commitment across occupational groups: A meta -analysis, Journal of Organizational Behaviour, 13, 1992, 539-544

[2] J.P. Meyer, , D.J. Stanley, L. Herscovitch. and L. Topolnytsky, Affective, continuance, and normative commitment to the organization:A meta-analysis of antecedents, correlates, and consequences. Journal of Vocational Behavior, 61(), 2002, $20-52$.

[3] L.J. Williams, and, J.T. Hazer "Antecedents and consequences of satisfaction and commitment in turnover models: a re-analysis using latent variable structural equation methods", Journal of Applied Psychology, 71 (2) 1986, 219-31.

[4] T.S. Bateman,, and, S. Strasser, "A longitudinal analysis of the antecedent of organizational commitment" Academy of management journal, 27(1) (1984), 95-112

[5] J.H. \& J.D, Generalizability of an organizational commitment mode1, Academy of Management Journal, 24(3), (1981), 512-526.

[6] N. J. Allen and , J.P. Meyer, Organizational socialization tactics: A longitudinal analysis of links to newcomers' commitment and role orientation. Academy of Management Journal, 33(), (1990), 847-858

[7] A. Cohen, E. Ben-Tura and D. R. Vashdi, The relationship between social exchange variables, OCB, and performance: What happens when you consider group characteristics?", Personnel Review, 41( 6), 705 - 731

[8] C. Brod, Technostress: The human cost of computer revolution, Reading, MA: Addison-Wesley, (1984)

[9] P. A. Tiemo, O. J. Owajeme Technostress: Causes, symptoms and coping strategies among Librarians in University libraries, Educational Research, 1(12) 2010, 713-720

[10] A. N. Çoklar and Y. L. Şahin, Technostress Levels of Social Network Users Based on ICTs in Turkey European Journal of Social Sciences, 2 (2), 2011.

[11] J. P. Meyer \& N,J. Allen, A three-component conceptualization of organizational commitment: Human Resource Management Review, 1, 1991. 61-89.

[12] R.T. Mowday, R.M. Steers and L.W. Porter, The measurement of organizational commitment, Journal of Vocational Behavior, 14, $1979,224-247$.

[13] R. S.S. Lazarus and Folkman, Stress, Appraisal and Coping. (Springer, New York, 1984)

[14] H. Zannad, \& V. Rouet, Organizational Commitment in Innovative Companies Organizational Commitment In Innovative Companies, (2003), 1-25.

[14] W. Eta, A. Umar, M.B. Aliyu, The Mediating Roles of Organizational Commitment on the Relationship between Innovation Characteristics and the Technology Adoption in the Nigerian SMEs: Setting a New Research Agenda, Research Journal of Science and IT management, 2(8), 2013, 43-50

[15] C. Estay, Identity and organizational commitment: working paper, Graduate school of Bordeaux, Larema, 2001, 6-17.

[16] R. Muthuveloo, \& R.C. Rose, Antecedents and outcomes of organizational commitment among Malaysian engineers, American Journal of Applied Sciences, 2 (6), 2005, 1095 - 1100.

[17] M. Vakola \& I. Nikolaou Attitudes towards organizational change: What is the role of employees' stress and commitment? Employee Relations, 27 (2), 2005, 160-174.

[18] A.D. Szilagyi, \& M.J. Wallace, Organizational Behavior and Performance (2Ed) (Goodyear Publishing Company, Santa Monica, CA, 1980).

[19] W. R. Rowden, \& T. C. Conine, "The Impact of Workplace Learning on Job Satisfaction in Small US Commercial Banks", Journal Of Workplace Learning, 17(4) 2005.

[20] M. Weil \& L. Rosen, TechnoStress: Coping With Technology@Work@Home@Play (John Wiley \& Sons, New York, 1997).

[21] P.J. Meyer \& J. N. Allen, Testing the side bet theory of organizational commitment:Some methodological considerations, Journal of Applied Psychology, 69, 1984, 372-378.

[22] R. S. Snell, "The Learning Organization, Sense-giving and Psychological Contracts: A Hong Kong Case", Organization Studies, 23(4) , 2002, 549 .

[23] A. A. Ketchand \& J.R. Strawser, Multiple dimensions of organizational commitment: implications for future accounting research.Behavioral Research in Accounting, 13, 2001, 221-51. Retrieved October 7/2013 from http://www.accessmylibrary.com/coms2/summary

[24] R. B.Lopopolo, The relationship of role-related variables of job satisfaction and commitment to the organization in a restructured hospital, 25 environment Physical Therapy, 82(10), 2002, 984-999.

[25] L. A. Ennis, "The Evolution of Techno Stress" (Computers in Libraries, 2005) 10-12.

[26] P. E. Brillhart, Technostress in the workplace: Managing stress in the electronic workplacell, Journal of American Academy of Business, 5 (2), 2004, 302-307.

[27] N. Davis-Millis, Technostress and the organization: A manager's guide tosurvival in the information age. Paper presented at the 67th Annual Meeting of the Music Library Association, 14 February, 2011., Boston, Massachusetts. Retrieved from http://web.mit.edu/ninadm/www/mla.htm

[28] A. Ashour, "A framework of a cognitive-behavior theory of leader influence and effectiveness," Organizational Behavior and Human Performance (30) 1982, 407-430. 
[29] F. Gerr, C.P. Monteilh, and M. Marcus, Keyboard use and musculoskeletal outcome among computer users, Journal of Occupational Rehabilitation, 2006. 16(3)2006, 265-277

[30] M. Tarafdar, Tu, Q., Ragu-Nathan, B. S., and Ragu-Nathan, T. S. The impact of technostress on role stress and productivity, Journal of Management Information Systems, 24(1) 2007, 301-328.

[31]. J. Nawe, Work-related stress among the library and information workforce, Library ReviewSingapore Journal of Library \& Information Management, , 44 (6), 1995.

[32] R. Ayyagari, (2011) V. Grover and R.L. Purvis, Technostress: Technology antecedents and implications, MIS Quarterly, 35 (4) 2011,831-858.

[33] R. F. Chisholm, S. V. Kasl, and B. Eskenazl, The nature and predictors of job related tension in a crisis situation: Reactions of nuclear workers to the Three Mile Island accident, Academy of Management Journal, 26, () 1983, 385-405.

[ 34 J. Moore, "One Road to Turnover: An Examination of Work Exhaustion in Technology Professionals.," MIS Quarterly, 24(1) 2000, 141-168.

[35] C.O. Longenecker, C.J. Schaffer and J.A. Scazzero, "Causes and consequences of stress in IT profession," Information Systems Management, 16(3) 1999.

[36] V. Sethi, R. King and J., Quick What causes stress in information system professionals? Communications of the ACM, 47(3) 2004, 99-102.

[37] C.L. Cooper, P. J.Dewe and M. P .O'Driscoll, Organizational Stress Sage Publications, Thousand Oaks, CA, 2001.

[38] S. Thomée, Occupational and Environmental Medicine, master's thesis, Institute of Medicine at Sahlgrenska Academy, University of Gothenburg,, 2012

[42] J. Cohen, Statistical power analysis for the behav-ioral sciences (Hillsdale, N. J. Erlbaum, 1988).

[43] J. pallant, J SPSS survival Manual: A step by step guide todata analysis using SPSS( Printed in China at Everbest Printing Co.,2011) 4th edition.

[44] J. S. Wrench \& M.P. Narissra, Carter the Relationship between Computer-Mediated-Communication Competence, Apprehension, Self-Efficacy, Perceived Confidence, and Social Presence, Southern Communication Journal, 72 (4) 2007, 355-378

[45] E.A. Locke and G. P. Latham, A theory of goal setting and task performance ( Englewood Cliffs, NJ: Prentice-Hal, 1990) 